\title{
Failure Theories of Fiber Reinforced Polymer Laminates
}

\author{
B.Elamvazhudi, S.Gopalakannan
}

\begin{abstract}
Theoretically predicting the service life of the Fiber Reinforced Polymer (FRP) laminates is important to design safe structural components. In common, failure of FRP laminates includes fiber/matrix cracking, delamination of fibers, debonding of reinforcement materials, and matrix failure due to stress gradients. Conventionally failure envelops of the FRP laminates are strongly depends upon maximum stress criterion and normal strain criterion. This review paper reveals the all the failure prediction theories based on stress and strain induced in laminates. This article covers the recent well established failure prediction theories and common modeling approaches of fiber reinforced polymer composites.
\end{abstract}

Index Terms: Service life, Failure theories, Laminates, Stress criterion, Strain criterion

Notations
$\begin{array}{ll}\text { Eo } & \text { Unidirectional laminate modules } \\ \mathrm{Fi}, & \text { Strength parameters } \\ \mathrm{R} & \text { Design factor } \\ \sigma \mathrm{\sigma i}, \sigma \mathrm{j} & \text { Stress components } \\ \mathrm{E}_{\mathrm{A}} & \text { Axial Elasticity modulus } \\ \mathrm{E}_{\mathrm{T}} & \text { Transverse Elasticity modulus } \\ \gamma & \text { Poisson's ratio } \\ \varepsilon & \text { Normal strains } \\ \mathrm{X}_{\mathrm{T}} ; \mathrm{X}_{\mathrm{C}} & \text { Tensile strength and compressive strength } \\ \mathrm{S}_{21} & \text { Shear strength }\end{array}$

\section{INTRODUCTION}

Over the past four decades, researchers are trying to predict the failure of unidirectional and multidirectional composite laminates under complex loading numerically, Because of finding failure through numerical predictions gain more and more importance in order to avoid costly experiments and time. Numerous failure theories and approaches have formulated for failure prediction of fiber reinforced polymer composites and had differences in terms of modeling methodology, and assumptions used to derive it. Although it is clear that, no criterion is universally accepted by designers as adequate and appropriate under combined loads and nonlinear conditions. This review paper discusses about the failure of FRP laminates and the state- of - the- art failure prediction theories that are generally used by the designers and researchers to date. Failure is generally defined as loss of

\footnotetext{
Revised Manuscript Received on October 30, 2019.

* Correspondence Author

B.Elamvazhudi*, Dept.of Mechanical Engineering, IFET College of Engineering, Villupuram, India.

S.Gopalakannan, Dept.of Mechanical Engineering, Adhiparasakthi Engineering College, Chennai.

(C) The Authors. Published by Blue Eyes Intelligence Engineering and Sciences Publication (BEIESP). This is an open access article under the CC
} BY-NC-ND license (http://creativecommons.org/licenses/by-nc-nd/4.0/) load withstanding ability of a component or material and it will be examined in different scales i.e. at micro-mechanical, lamina level, and laminate level (see Fig.1). In the micro-mechanical level, fibers and the matrix are treated as separate materials with different constitutive behavior (see Fig.1a). In this level, fiber-matrix and fiber-fiber interactions were studied. In lamina level (ref. Fig.1b), the fiber-matrix composites regarded as a homogeneous material but anisotropic material. On the laminate level (ref. Fig.1c), the material is regarded as a stacked composition of several lamina including their interfaces and the orientation of the individual lamina mentioned by angle $\theta$.

\begin{tabular}{|c|c|c|}
\hline $\begin{array}{c}\text { 1a.Micromechanical } \\
\text { level }\end{array}$ & $\begin{array}{c}\text { 1b. Lamina } \\
\text { level }\end{array}$ & $\begin{array}{c}\text { 1c. } \\
\text { Laminate } \\
\text { level }\end{array}$ \\
\hline & & \\
\hline
\end{tabular}

Fig. 1 Different scale of laminates

Also the damage mechanisms are generally categorized as: 1 . Micro-level damage mechanisms 2. Macro-level damage mechanisms 3. Coupled micro-macro-level damage mechanisms (ref. Fig. 2)

\section{LAMINA FAILURE CRITERIA}

In orthotropic/anisotropic composite lamina the damage mechanisms and mechanical properties are changes with the direction of applied load and loading conditions. Typically failure does not occur by yielding but it occurs due to the fracture of one of the constituents such as matrix or fibers or the fiber-matrix interface. Generally Failure criteria of composites laminates are classified based on the stress interaction of laminates and considered into two groups: (1) Non-Interactive failure criteria (2) Interactive Failure Criteria. Non-interactive failure Criteria can be defined as the one having no interactions between stresses or strain components. Failure prediction criteria normally based on two theories i.e. 1.Maximum stress criteria 2. Maximum strain criteria.

\section{A. Maximum Stress Criteria}

According to this theory, failure occurs if one of the stress components along with the principal material axes exceeds the corresponding strength in that direction. Maximum stress theory is more appropriate for brittle materials.

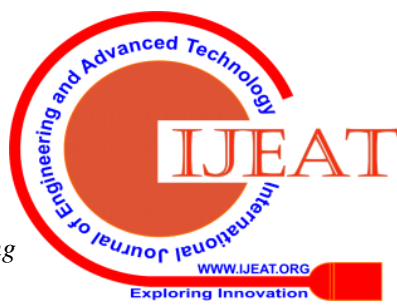




\section{Failure Theories of Fiber Reinforced Polymer Laminates}

Failure of individual plies under transverse and tension loads is exactly described by a maximum-stress criterion and it can be expressed by the Equations (1) \& (2) and described below

and

$$
\begin{aligned}
& \sigma_{11}=\mathrm{X}_{\mathrm{L}} \text { when } \sigma_{11} \geq 0 \\
& \text { - } \mathrm{X}_{\mathrm{T}} \text { when } \sigma_{11} \leq 0
\end{aligned}
$$

$$
\begin{array}{r}
\sigma_{22}=\mathrm{Y}_{\mathrm{L}} \quad \text { when } \sigma_{22} \geq 0 \\
-\mathrm{Y}_{\mathrm{T}} \quad \text { when } \sigma_{22} \leq 0
\end{array}
$$

\section{B. Maximum Strain Criteria}

According to this theory, if the strain components of a material along with the principal material axes exceed corresponding ultimate strain in loading direction then the material will fail. Generally the strain criterion is expressed in terms of stress components. The induced stress component has small interaction between longitudinal and lateral stress due to Poisson effect. Failure Conditions can be expressed by the Equations (3) \& (4) as given below

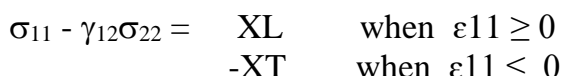

and

$$
\sigma_{22}-\gamma_{21} \sigma_{11}=\text { YL } \quad \text { when } \varepsilon 22 \geq 0
$$

\section{DIFFERENT FAILURE CRITERIA AND APPROACHES}

\section{CHAMIS CRITERIA [1]}

This theory used to predicts the uniaxial strengths of the composite from its constituent material properties with fabrication process considerations. Strength of laminates determined by modified rule of mixtures relation, matrix-strain magnification factors, and maximum void effects. Another form of this theory is based on a modified distortion energy principle. The criterion is applicable to orthotropic / anisotropic and isotropic materials.

\section{HART-SMITH'S CRITERIA [2]}

These criteria illustrates that how the classical maximum shear strength of isotropic metals assumed to be orthotropic materials such as carbon fibers, glass fibers and fiber-reinforced polymer composites. Hart-Smith's criteria proposed two models which are: 1. Generalized Tresca model: which consider shearing of the fiber is the dominant failure mode 2. Maximum Strain model: is a 2-D interpretation of failure of laminates with an assumption to neglect the initial failure. This criterion is applicable for fiber reinforced in more than two reinforcement directions and the failure of laminates described by the Equations (5) to (9). Longitudinal tensile failure:

$$
\varepsilon_{1}=\varepsilon_{1 T}
$$

Longitudinal compressive failure:

$$
\varepsilon_{1}=\varepsilon_{1 C}
$$

In-plane shear failure:

$\mathrm{S} 12=\mathrm{XT} / 20$ or $\mathrm{XC} / 20$ whichever is the greatest

Transverse tension:

$\mathrm{YT}=\mathrm{XT} / 10$ or $\mathrm{XC} / 10$ whichever is the greatest

Transverse compression:

$\mathrm{YC}=\mathrm{XT} / 10$ or $\mathrm{XC} / 10$ whichever is the greatest

\section{ECKOLD's CRITERIA [3]}

This is strain based criterion and it considers the attributes of composite failures necessary for the design environment. Efforts have been taken to calculate ultimate strength and this criterion ignores material non-linearity and difference in tensile and compressive properties of fiber reinforced laminates. This theory holds two key assumptions 1 . Strain in all directions is equally important 2. Transverse strains limited to $0 \cdot 1 \%$. A failure prediction by this theory is mostly unconservative, because of no account of non-linearity leads to prediction of strain is underestimating, and prediction of stiffness is overestimating. Strength values are measured from the modified quadratic failure criterion described by Equation (10)

$$
\begin{aligned}
& R^{2}\left\lfloor X_{L} \sigma_{11}{ }^{2}+2 Y_{L} Y_{T} \sigma_{11} \sigma_{22}+X_{T} \sigma_{22}{ }^{2}+S_{L T} \tau_{12}^{2}\right\rfloor+ \\
& R\left(X_{L} \sigma_{11}+X_{T} \sigma_{22}\right)-1=0
\end{aligned}
$$

\section{EDGE's CRITERIA [4]}

This criterion defines the Grant-Sanders method which is developed by the designers of British Aerospace for the prediction of failure in polymer laminates. This method is based on ply-by-ply analysis. This criterion gives acceptable values with the failure envelopes which are developed measured from the unidirectional laminates. All the failure theories are predicting both the mode and location of failure. This theory will hold good to envisage the nonlinear stress and strain curve of laminates. For initial failure of matrix material expressed by the equations (11) to (13) and the final failures described as equations (14) to (16).

For initial failure:

Matrix Tension

$$
\sigma_{22}=\mathrm{Y}
$$

Matrix Compression:

$$
\sigma_{22}=\text { YC }
$$

Combined Shear and Matrix Tension:

$$
\left(\frac{\sigma_{22}}{Y_{L}}\right)^{2}+\left(\frac{\tau_{12}}{S_{12}}\right)^{2}=1
$$

For final failure:

Fiber Tension:

$$
\sigma_{11}=\mathrm{XL}
$$

Matrix Compression:

$$
\sigma_{11}=\mathrm{XT}
$$

Combined Shear and Fiber Compression:

$$
\left(\frac{\sigma_{11}}{X_{T}}\right)+\left(\frac{\tau_{12}}{S_{L T}}\right)=1
$$

\section{MCCARTNEY THEORY [5]}

McCartney find a new way of predicting the induced stresses magnitude of transverse cracks of cross-ply laminates under biaxial loading conditions and considering both anisotropy and thermal stress based damage. In this theory, crack initiation and growth parameters are discussed at the macroscopic level and assume that laminate deformations are depicted by linear elasticity theory. 
Further assumed that the cracks develop in one orientation and it leads to fracture of transverse plies ruled by energy balance principles. This criterion expresses transverse tensile cracking by the equation (17)

$$
\sigma+k \sigma_{t}>\sqrt{\frac{4 p \gamma}{E_{A}(2 p)}-\frac{1}{E_{A}(p)}}+\overline{\sigma_{0}}
$$

\section{TSAI-HILL THEORY [6]}

Hill modified the Azizi and Tsai formulated Criteria. This criterion describes the strength characteristics of quasi-homogeneous, orthotropic composite laminates. This theory gives details that, the strength all the unidirectional composite materials are governed by axial, transverse, and shear strength, and the angle of fiber orientation of each constituent layer and the temperature at which the laminate is cured. Also this theory depicts that process of laminations induces residual stress in the laminates and the subsequent effect like stress distribution under external load, method for determining the strength of angle-ply composites and failure described by the equation (18)

$$
\frac{\sigma_{11}^{2}}{F_{1}^{2}}+\frac{\sigma_{22}^{2}}{F_{2}^{2}}+\frac{\tau_{12}^{2}}{F_{6}^{2}}-\frac{\sigma_{11} \sigma_{22}}{F_{1}^{2}}=1
$$

\section{TSAI-WU THEORY [7]}

Tsai-Wu theory is based on Goldenblat and Koponov's model. This theory considering both tensile and compressive stress of laminates and acceptable to the computational method of stress invariants. Tsai-Wu theory is commonly used to predict the failure mechanism because of easy to use and caters the three dimensional failure cases and the failures described by the Equation (19).

$$
\begin{aligned}
& \left(\frac{1}{X_{L}}-\frac{1}{X_{T}}\right) \sigma_{11}+\left(\frac{1}{Y_{L}}-\frac{1}{Y_{T}}\right) \sigma_{22}+\frac{1}{X_{L} X_{T}} \sigma_{11}{ }^{2}+ \\
& \frac{1}{Y_{L} Y_{T}} \sigma_{22}{ }^{2}+\frac{1}{S^{2}{ }_{L T}} \tau_{12}{ }^{2}-\frac{\sigma_{11} \sigma_{22}}{\sqrt{X_{L} X_{T} Y_{L} Y_{T}}}=1
\end{aligned}
$$

\section{HASHIN - ROTEM CRITERIA [8]}

This criterion is mainly used for finding the fatigue behavior of unidirectional laminates and this criterion proposes two basic failure mechanisms. i. Fiber failures ii. Matrix failures. Fiber failures are due to the axial stresses and the matrix failures is due to the transverse and shear stresses. This approach has a reasonable assumption that no fiber breakage mechanisms involved. Attempt was not made to find stress interaction between laminas and its effects on delamination failure or about degradation of properties when the limit values of the criterion are reached. Hashin-Rotem criterion specified by the equations (20) and (21)

$$
\begin{gathered}
\frac{\sigma_{11}}{X}=1 \\
\left(\frac{\sigma_{T}}{Y}\right)^{2}+\left(\frac{\tau}{S}\right)^{2}=1
\end{gathered}
$$

\section{PUCK CRITERIA [9]}

The Puck criterion is follows the theory of Coulomb and Mohr and modified by Paul. According to puck theory, based on the fiber properties failure mechanism was identified. In addition, matrix failure was categorized into three set of stress states i. Transverse tension ii. Moderate transverse compression iii. Large transverse compression. Fiber and matrix failures under tension and compression are specified by the equations (22) to (25).

Fiber failure in tension:

$$
\frac{1}{\varepsilon_{1 T}}\left(\varepsilon_{1}+\frac{V_{f 12}}{E_{f 1}} m_{\sigma f} \sigma_{22}\right)=1
$$

Fiber failure in compression:

$$
\frac{1}{\varepsilon_{1 C}}\left|\left(\varepsilon_{1}+\frac{V_{f 12}}{E_{f 1}} m_{\sigma f} \sigma_{22}\right)\right|+\left(10 \gamma_{21}\right)^{2}=1
$$

Matrix failure in transverse tension:

$$
\sqrt{\left(\left(\frac{\tau_{21}}{S_{21}}\right)^{2}+\left(1-p_{\gamma p}^{+} \frac{Y_{T}}{S_{21}}\right)^{2}\left(\frac{\sigma_{22}}{Y_{T}}\right)^{2}\right)}+p_{\gamma p}^{+} \frac{\sigma_{22}}{S_{21}}+\frac{\sigma_{11}}{\sigma_{11 D}}=1
$$

Matrix failure in transverse compression:

$$
\frac{1}{S_{21}}\left(\left(\sqrt{\tau_{21}^{2}+\left(p_{\partial p}^{-} \sigma_{22}\right)^{2}}\right)+p_{\not p}^{-} \sigma_{22}\right)+\frac{\sigma_{11}}{\sigma_{11 D}}=1
$$

\section{CUNTZE CRITERIA [10]}

This criterion deals with five failure mechanisms such as two fiber failures and three inter-fiber failures. Initial assumption in this theory is failure mechanisms exist due to probabilistic effects. Failure situations are based on failure mode concepts and equations of fiber failure expressed by (27) to (29). Transversal tensile failure:

$$
\frac{\sigma_{2}}{E_{f f}^{\perp \sigma} \cdot R_{\perp}^{t}}=1
$$

Wedge failure:

$$
\frac{\left(b_{\perp}^{\tau}-1\right)\left(\sigma_{2}+\sigma_{3}\right)}{E_{f f}^{\perp \tau} R_{\perp}^{t}}+\frac{b_{\perp}^{t}\left(\sigma_{2}-\sigma_{3}\right)^{2}+b_{\perp}^{t} \cdot \tau_{21}^{2}}{\left(E_{f f}^{\perp \tau} R_{\perp}^{t}\right)^{2}}=1
$$

Inter fiber failure:

$$
\frac{\tau_{21}^{3}+b_{\perp} 2 \sigma_{2} \tau_{21}^{2}}{\left(E_{f f}^{\perp \tau} R_{\perp}^{t}\right)^{3}}=1
$$

\section{SUN CRITERIA [11]}

In this theory, the final laminate failure is predicted without neglecting shear strength of laminates. In determining failure strength under pin load conditions non linear shear stress strain expression significantly considered (Refer Eqn. 30). Sun criterion discloses that without evaluating current stress of laminates, strength of laminates can not be calculated.

$$
\left(\frac{\sigma_{x}}{X}\right)^{2}+\frac{\frac{\sigma_{x y}^{2}}{2 G_{x y}}+\frac{3}{4} a \sigma_{x y}^{4}}{\frac{S^{2}}{2 G_{x y}}+\frac{3}{4} a S^{4}}=e^{2}
$$

If $\mathrm{e} \geq 1$ material fail

e $<1$ material will not fail 


\section{Failure Theories of Fiber Reinforced Polymer Laminates}

\section{WOLFE'S CRITERIA [12]}

This theory obtained from the maximum stress theory and factors such as unloading behaviour of cracked laminates and geometric nonlinearity were considered. Based on this theory,

initial and final fiber failure points coincide in a single location. For the prediction of fiber failure (Refer equation 31) and matrix failure, (Refer equation 32) the functional is differentiated with respect to strain variable.

Fiber failure:

$$
\left[\frac{\int_{\varepsilon_{1}} \sigma_{11} d \varepsilon_{11}}{\int_{\varepsilon_{1}^{M}} \sigma_{11} d \varepsilon_{11}}\right]^{m_{1}} /\left[\left[\frac{\int_{\varepsilon_{i}} \sigma_{i} d \varepsilon_{i}}{\int_{\varepsilon_{i}^{M}} \sigma_{i} d \varepsilon_{i}}\right]_{\geq 0.1}^{m_{1}}\right.
$$

Matrix failure:

$$
\left[\frac{\int_{\varepsilon_{1}} \sigma_{11} d \varepsilon_{11}}{\int_{\varepsilon_{1}^{M}} \sigma_{11} d \varepsilon_{11}}\right]^{m_{1}} /\left[\frac{\int_{\varepsilon_{i}} \sigma_{i} d \varepsilon_{i}}{\int_{\varepsilon_{i}^{M}} \sigma_{i} d \varepsilon_{i}}\right]_{<0.1}^{m_{1}}
$$

\section{ZiNOVIEV CRITERIA [13]}

Theory assumes that laminate ply deforms under both tensile and compressive forces. Stresses in laminates along the fiber direction exceeds their ultimate values (Refer equation 33 \& 34 ), and shear stress values (Refer equation 35), the ply is assumed to be broken.

Axial tension failure:

$$
\sigma_{1}=X_{T}
$$

Axial compression failure:

$$
\sigma_{1}=X_{C}
$$

In-plane shear failure:

$$
\tau_{12}=S_{12}
$$

\section{KROLL-HUFENBACH [14]}

This criterion provides calculation of maximum stress of laminated plates with circular notches from the experimental tensile fracture test. This theory reveals that notch dimensions and stress concentration factors are not enough for reliably predict the strength of notched laminates. In this theory, calculation procedures are explained based on fundamental elasticity theory.

\section{MAYES THEORY [15]}

It's a three dimensional failure calculation method based on multi-continuum theory (MCT) to obtain constituent material failure mechanisms. In this theory when one of the constituent fails, keep other constituents to distribute the load to entire structure. Fiber failures and matrix failure are described by the equation (36) and (37). The stiffness and strength of damaged areas can be reduced without necessarily declaring total structural failure.

Fiber failure:

$$
K_{1 f} I_{1 f}^{2}+K_{4 f} I_{4 f}=1
$$

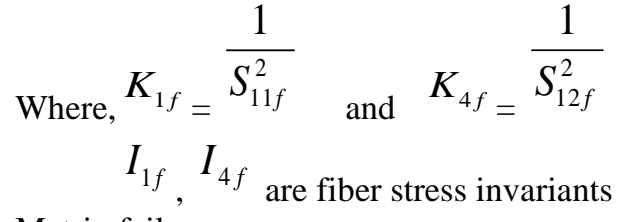

Matrix failure:

$$
K_{3 m} I_{3 m}+K_{4 m} I_{4 m}=1
$$

$$
\text { Where, } \begin{gathered}
K_{3 m}=\frac{1}{S_{22 m}^{2}+S_{33 m}^{2}} \text { and } K_{4 m}=\frac{1}{S_{12 m}^{2}} \\
I_{3 m}, I_{4 m} \text { are matrix stress invariants }
\end{gathered}
$$

\section{HUANG THEORY [16]}

This theory describes simulation methodology of laminated composites subjected to various biaxial loads based on micromechanics model and classical laminate theory. Stress induced in fiber and matrix materials are completely described by this theory. Thermal effect can be considered. Fiber failure, matrix failure and ply failure can be clearly identified by the equations (38) and (39).

\section{Fiber failure:}

$$
\begin{aligned}
\sigma_{\mathrm{eq}}=\quad\{\sigma(1) & \text { when } \sigma(2) \leq 0, \\
& {[\{(\sigma(1)) \mathrm{q}+(\sigma(2)) \mathrm{q}] 1 / 4 \leq 0, \text { when } \sigma(6)>0,}
\end{aligned}
$$

where $\sigma(1)$ and $\sigma(2)$ are fiber stresses in longitudinal and transverse direction

\section{Matrix failure:
$\sigma \mathrm{eq}=\{\sigma(1)$ when $\sigma(2) \leq 0$, $\{[\{(\sigma(1)) \mathrm{q}+(\sigma(2)) \mathrm{q}] 1 / 4$, when $\sigma(6)>0$}

Where $\sigma(1)$ and $\sigma(2)$ are matrix stresses in longitudinal and transverse direction

\section{BOGETTI CRITERIA[17]}

This maximum Strain failure criterion follows 3D maximum strain failure approach and predicts nonlinear shear stress-strain curve of laminates coupled with progressive-ply failure methodology. This criterion describes laminates principal ply strains in six directions $(\varepsilon 1, \varepsilon 2, \varepsilon 3, \varepsilon 4, \varepsilon 5$, and ع6) compared to their corresponding allowable maximum strain:

if $\varepsilon 1>0, \varepsilon 1>Y 1 T$, tensile fiber failure

if $\varepsilon 1<0,|\varepsilon 1|>\mathrm{Y} 1 \mathrm{C}$, compressive fiber failure

if $\varepsilon 2>0, \varepsilon 2>\mathrm{Y} 2 \mathrm{~T}$, transverse tension failure

if $\varepsilon 2<0,|\varepsilon 2|>Y 2 C$, transverse compression failure

if $\varepsilon 3>0, \varepsilon 3>\mathrm{Y} 3 \mathrm{~T}$, transverse tension failure

if $\varepsilon 3<0, \varepsilon 3 \mid>Y 3 C$, transverse compression failure

if $\varepsilon 4 \mid>$ Y23 inter-laminar shear failure

if $|\varepsilon 5|>Y 13$, interlaminar shear failure

if $|\varepsilon 6|>Y 12$, in-plane shear failure

This criterion expresses strain failures explicitly in terms of three parameters based on Ramberg-Osgood equation (refer equation 40).

$$
\sigma=\frac{E_{o} \varepsilon}{\left(1+\left(\frac{E_{o} \varepsilon}{\sigma_{o}}\right)^{n}\right)^{\frac{1}{n}}}
$$




\section{MOHR-COULOMB (M-C) CRITERION [18]}

This criteria is suitable in the case of fracture occurs under tension loading. The application of the $\mathrm{M}-\mathrm{C}$ criterion is to predict multiaxial failure of matrix materials. This criterion is inadequate in the case of failure prediction of chopped glass fiber reinforced epoxy based laminates subjected to pressure loading. Micromechanical model based on this criterion is to predict the strength properties of fiber composites.

\section{LARC03 CRITERIA FOR MATRIX FAILURE [19]}

Criteria based on concepts developed by Hashin and Puck criteria. It focuses on $\mathrm{M}-\mathrm{C}$ stresses induced in the matrix material which are always on crack planes normal to plies and parallel to fibers. In case of compression, the crack plane may not be normal to ply direction. Inclination of the fracture plane must be known in order to apply this criterion.

\section{LARC03 CRITERIA FOR FIBER FAILURE [20]}

Based on the experimental results, puck proposed a failure prediction theory for fiber failure under tensile loading conditions. Theory is based on the maximum strain acting along the fibers under the applied tensile load. This criterion holds good and simple to predict the failure of laminates.

\section{FAILURE THEORIES RESULTS AND COMPARISONS}

Twenty approaches ranked highly by the quantitative assessment procedure followed by different approaches and their general capabilities were listed in Table I below.

Table.1Failure Theories Comparison

\begin{tabular}{|c|c|c|}
\hline Failure theories & Attempt to predict & Fail to predict \\
\hline Chamis & $\begin{array}{l}\checkmark \text { laminate strength } \\
\checkmark \text { Fiber failure } \\
\text { prediction } \\
\checkmark \text { 3D stress analysis }\end{array}$ & $\begin{array}{l}\checkmark \text { Shape of stress strain } \\
\text { curves } \\
\checkmark \text { Maximum shear stress }\end{array}$ \\
\hline Hart-Smith J & $\begin{array}{l}\checkmark \text { laminate strength } \\
\checkmark \text { Elastic constants } \\
\text { prediction } \\
\checkmark \text { Fiber failure } \\
\text { prediction }\end{array}$ & $\checkmark$ initial stiffness \\
\hline Eckold GC & $\begin{array}{l}\checkmark \text { Lamina and laminate } \\
\text { strength } \\
\checkmark \text { Elastic constants } \\
\text { prediction } \\
\checkmark \text { Computer code } \\
\text { generation }\end{array}$ & $\begin{array}{l}\checkmark \text { Shear strength } \\
\text { prediction }\end{array}$ \\
\hline Edge EC & $\begin{array}{l}\checkmark \text { laminate strength } \\
\checkmark \text { Non-linear analysis } \\
\checkmark \text { Deformation } \\
\text { prediction } \\
\checkmark \text { Initial strength } \\
\text { prediction }\end{array}$ & $\begin{array}{l}\checkmark \text { Stress -strain curves } \\
\text { under large strain } \\
\text { conditions }\end{array}$ \\
\hline $\begin{array}{l}\text { McCartney } \\
\text { theory }\end{array}$ & $\begin{array}{l}\checkmark \text { Laminate strength } \\
\text { prediction } \\
\checkmark \text { Crack density } \\
\text { prediction }\end{array}$ & $\checkmark$ Shear strength \\
\hline $\begin{array}{l}\text { Tsai-Hill } \\
\text { Theory }\end{array}$ & $\begin{array}{l}\checkmark \text { Laminate strength } \\
\text { prediction } \\
\checkmark \text { Deformation } \\
\text { prediction } \\
\checkmark \text { 3D stress analysis }\end{array}$ & $\checkmark$ nonlinear behaviour \\
\hline $\begin{array}{l}\text { Tsai-Wu } \\
\text { Theory }\end{array}$ & $\begin{array}{l}\checkmark \text { Lamina and laminate } \\
\text { strength } \\
\checkmark \text { Deformation } \\
\text { prediction } \\
\checkmark \text { Computer code } \\
\text { generation }\end{array}$ & $\checkmark$ final strain \\
\hline
\end{tabular}

\begin{tabular}{|c|c|c|}
\hline $\begin{array}{l}\text { Hashin-Rotem } \\
\text { criteria }\end{array}$ & $\begin{array}{l}\checkmark \text { Elastic laminate } \\
\text { constants } \\
\checkmark \text { Laminate strength } \\
\text { prediction } \\
\checkmark \text { Non-linear analysis }\end{array}$ & $\checkmark$ Stiffness \\
\hline Puck criteria & $\begin{array}{l}\checkmark \text { laminate strength } \\
\checkmark \text { Elastic laminate } \\
\text { constants } \\
\checkmark \text { Non-linear analysis }\end{array}$ & $\checkmark$ Deformation \\
\hline Cuntze criteria & $\begin{array}{l}\checkmark \text { Non-linear analysis } \\
\checkmark \text { Deformation } \\
\text { prediction } \\
\checkmark \text { Computer code } \\
\text { generation }\end{array}$ & $\checkmark$ Final strain \\
\hline Sun criteria & $\begin{array}{l}\checkmark \text { Non-linear analysis } \\
\checkmark \text { laminate strength } \\
\text { prediction } \\
\checkmark \text { Elastic laminate } \\
\text { constants }\end{array}$ & $\checkmark$ nonlinear behaviour \\
\hline $\begin{array}{l}\text { Wolfe's } \\
\text { Criteria }\end{array}$ & $\begin{array}{l}\checkmark \checkmark \text { Lamina and laminate } \\
\text { strength } \\
\checkmark \text { Elastic laminate } \\
\text { constants } \\
\checkmark \text { Non-linear analysis } \\
\checkmark\end{array}$ & $\checkmark$ Final strains \\
\hline $\begin{array}{l}\text { Zinoviev } \\
\text { Criteria }\end{array}$ & $\begin{array}{l}\checkmark \text { Lamina strength } \\
\text { prediction } \\
\checkmark \text { large deformation } \\
\text { prediction } \\
\checkmark \text { Initial strength } \\
\text { prediction }\end{array}$ & $\begin{array}{l}\checkmark \text { Nonlinear behaviour } \\
\text { not taken into account }\end{array}$ \\
\hline $\begin{array}{l}\text { Kroll-Hufenbac } \\
\text { h }\end{array}$ & $\begin{array}{l}\checkmark \text { Elastic constants } \\
\checkmark \text { Lamina strength } \\
\text { prediction }\end{array}$ & $\checkmark$ large strains \\
\hline Mayes theory & $\begin{array}{l}\checkmark \text { Lamina strength } \\
\text { prediction } \\
\checkmark \text { Elastic laminate } \\
\text { constants }\end{array}$ & $\checkmark$ final strains \\
\hline Hyuang theory & $\begin{array}{l}\checkmark \text { Lamina strength } \\
\text { prediction } \\
\checkmark \text { Elastic laminate } \\
\text { constants } \\
\checkmark \text { Initial strength } \\
\text { prediction } \\
\checkmark \text { 3D stress analysis }\end{array}$ & $\checkmark$ Residual stresses \\
\hline Bogetti criteria & $\begin{array}{l}\checkmark \text { Lamina strength } \\
\text { prediction } \\
\checkmark \text { shear stress-strain } \\
\quad \text { analysis }\end{array}$ & $\begin{array}{l}\checkmark \quad \text { residual thermal } \\
\text { stresses }\end{array}$ \\
\hline $\begin{array}{l}\text { Mohr-Coulomb } \\
\text { (M-C) criterion }\end{array}$ & $\begin{array}{l}\checkmark \text { Lamina strength } \\
\text { prediction } \\
\checkmark \text { Deformation } \\
\text { prediction }\end{array}$ & $\begin{array}{l}\checkmark \quad \text { Not applicable } \\
\text { for chopped fibers }\end{array}$ \\
\hline $\begin{array}{l}\text { LaRC03 } \\
\text { CRITERIA for } \\
\text { Matrix Failure }\end{array}$ & $\begin{array}{l}\checkmark \text { Lamina strength } \\
\text { prediction } \\
\checkmark \text { Deformation } \\
\text { prediction }\end{array}$ & $\checkmark$ final strain \\
\hline $\begin{array}{c}\text { LaRC03 } \\
\text { Criteria for } \\
\text { Fiber Failure }\end{array}$ & $\begin{array}{l}\checkmark \text { Lamina strength } \\
\text { prediction } \\
\checkmark \text { Deformation } \\
\text { prediction }\end{array}$ & $\checkmark$ final strain \\
\hline
\end{tabular}

\section{CONCLUSION}

This review illustrates that majority of the failure theories follows common procedure for predicting strength and generally failures are controlled by tensile failure of the fibers.

Published By:

Blue Eyes Intelligence Engineering

\& Sciences Publication 


\section{Failure Theories of Fiber Reinforced Polymer Laminates}

Current failure prediction methodologies have not addressed to represent the following topics

* Delamination initiation and propagation

* Buckling in thin walled structures

* Effects of ply stacking sequence

* Effect of loading and unloading behaviour

* Durability of laminates

* Degradation properties evaluation
Author-2 Photo

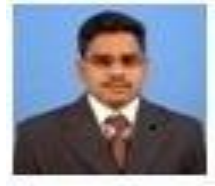

Dr. S.Gopalakannan has completed his Master degree in product design and Manufacturing from Pondicherry university. He is currently working as professor in Adhiparaskthi Engineering College, Chennai. He published Numerous internationa journals and attended no.of confereneces in india and abroad. His area of research is metal forming.

\section{REFERENCES}

1. Gotsis PK, Chamis CC, Minnetyan L. "Prediction of composite laminate fracture: micromechanics and progressive fracture", Compos Sci Tech,. Vol.58, 1137-50 (1998)

2. Hart-Smith LJ. "Predictions of the original and truncated maximum strain failure models for certain fibrous composite laminates", Compos Sci Tech, Vol.58: pp.1151-78 (1998)

3. Eckold GC. "Failure criteria for use in the design environment", Compos Sci Tech, Vol.58, 1095-1106 (1998)

4. Edge EC "Stress based Grant-Sanders method for predicting failure of composite laminates", Compos Sci Tech, Vol.58, 1043-1057(1998)

5. McCartney LN, "Predicting transverse crack formation in cross ply laminates", Compos Sci Tech, Vol.58, 1069-82(1998)

6. Tsai, S.W, "Strength Characteristics of Composite Materials", NASA CR-224(1965)

7. Liu K-S, Tsai SW, "A progressive quadratic failure criterion of a laminate", Compos Sci Tech, Vol.58, 1023-32(1998)

8. Rotem A, "Prediction of laminate failure with Rotem failure criterion", Compos Sci Tech, Vol.58, 1083-94(1998)

9. Puck A, Schurmann, "Failure analysis of FRP laminates by means of physically based phenomenological models", Compos Sci Tech Vol58,1045-68(1998)

10. Cuntze RG, Freund A, "The predictive capability of failure mode concept based strength criteria for multidirectional laminates", Compos Sci Tech, Vol64, 343-77(2004)

11. Sun CT, Tao JX, "Prediction of failure envelopes and stress strain behaviours of composite laminates", Compos Sci Tech , Vol.58, 1125-36(1998)

12. Wolfe WE, Butalia TS, "A strain energy based failure criterion for nonlinear analysis of composite laminates subjected to biaxial loading”, Compos Sci Tech, Vol.58, 1107-24(1998)

13. Zinoviev P, Grigoriev SV, Labedeva OV, Tairova LR, "Strength of multilayered composites under plane stress state", Compos Sci Tech ,vol.58, 1209-1224(1998)

14. Kroll L., Hufenbach, W, "Physically based failure criteria for dimensioning of thick walled Laminates", App Comp Mat, Vol.4, 321-332(1997)

15. S Mayes and A C Hansen, "Composite laminate failure analysis using multi continuum theory",Compos Sci Techno, Vol.64, 379-394(2004)

16. Z-m Huang, "A bridging model prediction of the tensile strength of composite laminates subjected to biaxial loads", Compos Sci Techno, Vol.64, 395-448(2004)

17. Travis A Bogette et al,"Predicting the nonlinear response and progressive failure of composite laminates", Jour. of Comp Mat, Vol.47(6-7):793-804(2013)

18. Kawabata, S "Strength of Epoxy Resin under Multiaxial Stress Field", ICCM-IV Conference, Tokyo, Japan(1982)

19. Fleck, N.A., and Liu, D., "Microbuckle Initiation from a Patch of Large Amplitude Fiber Waviness in a Composite under Compression and Bending," Euro. jour.of Mechanics, Vol.20, 23-37(2001)

20. Soutis, C., Smith, F.C., and Matthews, F.L., "Predicting the Compressive Engineering Performance of Carbon Fiber-Reinforced Plastics," Composites Part A: Applied Science and Manufacturing, Vol.31, 531-536(2000)

\section{Authors ProfiLe}

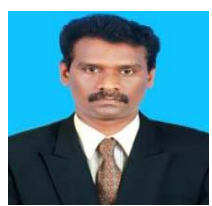

Mr. B.Elamvazhudi has completed his M.E.in Engineering Design from Anna university, Chennai. He is currently working as Associate professor in IFET College of Engineering College.He published many international journals and attended no.of confereneces and seminars. His area of research is polymer

composites. 